\title{
In memoriam: Dr. Alfonso Carriero
}

\section{Pescatori $\cdot$ S. D. Wexner}

(C) Springer-Verlag Italia 2014

We wish to share with the readers of the journal and the members of the Editorial Board our sorrow at the tragic premature death at the age of 55 of our friend Alfonso Carriero. Alfonso was an Italian colorectal surgeon who published interesting contributions on pelvic floor and hemorrhoidal diseases. His publications included a paper in Techniques in Coloproctology on the use of the Lonestar to facilitate $\mathrm{PPH}$, and two consensus papers in Colorectal Disease on PPH and STARR. He lectured in Italy and abroad. He was a Cleveland Clinic Florida alumnus and the chairman of the Coloproctology Unit of Modena, affiliated with the UCP Club. Alfonso was an extroverted and enthusiastic colleague who leaves behind his wife Silvia and his 7-year-old daughter Francesca.

M. Pescatori $(\bowtie)$

Rome, Italy

e-mail: ucpclub@virgilio.it

S. D. Wexner

Weston, FL, USA 